\title{
O uso do team-based learning como metodologia de ensino de saúde coletiva na graduação em odontologia
}

\section{Team-based learning as public health teaching methodology in undergraduate dentistry}

\author{
Ana Yeda Mendes Gonçalves \\ Cirurgiã Dentista pela Universidade Federal do Pará. E-mail: anayedag@ @otmail.com \\ Giselle Portal Rocha \\ Cirurgiã Dentista pela Universidade Federal do Pará. E-mail: gisa_portal@ hotmail.com \\ Kelly Lene Lopes Calderaro Euclides \\ Farmacêutica-Bioquímica, mestranda do Programa de Pós Graduação em Saúde, Ambiente e Sociedade da Universidade Federal do Pará. E-mail: \\ kellycalderaro@hotmail.com \\ Teresa Cristina Bordallo Farias \\ Médica, Docente do Instituto de Ciências da Saúde da Universidade Federal do Pará. E-mail: teresabordallo@uol.com.br \\ Liliane Silva do Nascimento, \\ Cirurgiã Dentista, Docente do Instituto de Ciências da Saúde da Universidade Federal do Pará. E-mail: lilianenascimento2001 @ gmail.com
}

\begin{abstract}
Resumo: O presente trabalho apresenta um estudo de método de ensino em odontologia frente à introdução de metodologia ativa para a prática pedagógica em saúde coletiva em curso de Odontologia. A proposta oportunizou discutir as características singulares de educação superior, com objetivo de avaliar o uso do team-based learning como estratégia metodológica de ensino. A metodologia de avaliação incluiu duas etapas, sendo observação não participante onde há posicionamento passivo do pesquisador e pesquisa de campo. Na primeira fundamentou-se o referencial teórico com definição de orientações, princípios e fundamentos da técnica; no segundo momento, registros em diário de campo e aplicação de roteiro de entrevista estruturada baseada em enfoque crítico-dialético. A amostra foi constituída por 150 alunos do curso de graduação de odontologia durante os anos de 2014 a 2016. Os resultados possibilitaram entender que a utilização da metodologia ativa estimula a participação protagonista do discente no processo de aprendizagem com ressignificação do conhecimento e possibilidade de avaliação imediata deste processo de aprendizado.
\end{abstract}

Palavras-chave: Educação Superior; Educação em Odontologia; Avaliação Educacional.

Abstract: The present study presents a study of the teaching method in dentistry in front of the introduction of an active methodology for the pedagogical practice in collective health in the course of dentistry. The proposal offered to discuss the unique characteristics of higher education in order to evaluate the use of team-based learning as a methodological teaching strategy. The evaluation methodology included two steps, being non-participant observation, where there is passive positioning of the researcher and field research. In the first one the theoretical reference was based with definition of orientations, principles and fundamentals of the technique; in the second moment, records in field diary and application of structured interview script based on a critical-dialectic approach. The sample was made up of 150 undergraduate dental students during the years 2014 to 2016. The results made it possible to understand that the use of the active methodology stimulates the protagonist participation of the student in the learning process with resignification of the knowledge and possibility of immediate evaluation of knowledge.

Keywords: Higher Education; Dentistry Education; Educational Evaluation. 


\section{INTRODUÇÃO}

O ensino de graduação em odontologia tem se mostrado preso a métodos tradicionais de aulas expositivas teóricas, laboratoriais e de extensa duração, evidenciando um cenário educativo ancorado na educação bancária, com métodos cartesianos (FREIRE, 2014). Porém, segundo o parecer 1300/01 do Conselho Nacional de Educação, os alunos dos cursos de graduação em saúde precisam aprender a aprender - o que engloba aprender a ser, aprender a fazer, aprender a viver juntos e aprender a conhecer, em que o educador reforça a capacidade crítica do educando, sua curiosidade, sua insubmissão (BRASIL 2001; CARCERERI et al., 2014; FREIRE, 2014).

As Diretrizes Curriculares Nacionais (DCNs) para a odontologia revelam a complexidade e a dinamicidade de todo o processo de ensino do curso para além da aquisição metódica do conhecimento. Assim, o egresso, essencialmente, deve possuir formação generalista, humanista, crítica e reflexiva para atuar em todos os níveis de atenção à saúde (BRASIL, 2001).

As atividades a serem desenvolvidas durante a formação em Odontologia privilegiam o trabalho em equipe, capacidade de comunicação, autonomia e emancipação do estudante como sujeito. Locus em que não cabe apenas preencher a função de reprodução de técnicas, estruturas e relações, dentro da aprendizagem, mas é preciso preencher com maestria o cenário educativo de modo a se fugir do "ensino tradicional, narrativo e depositário", que implica na vivência desumanizadora do acadêmico durante o curso universitário (MARIN et al. 2010; SISK, 2011; CARCERERI et al., 2014).

Hoje se sabe que o ensino não forma mais para a obediência ou reprodução de leis e atitudes, e sim traz novas finalidades através de um processo pedagógico centrado no aluno e produtor de autonomia (SISK, 2011; CARCERERI et al., 2014; FREIRE, 2014).

Essa visão evidencia um cunho emancipatório de ensinar e aprender, de modo que todos os componentes do ensino e aprendizagem integram-se ao processo de construção do conhecimento. Isso impõe ação metodológica ativa mais exigente, que por um lado permite compreender e, progressivamente, ensina a autonomia, de ser "construtor" de seu conhecimento (SISK, 2011).

A inserção das metodologias ativas no ensino da graduação ganhou espaço, inicialmente, internacional, mais precisamente nas áreas médicas, e consiste em encontrar soluções a problemas, com a adoção de formas participativas e colaborativas entre os discentes durante o processo de ensino (THOMPSON et al. 2007).

As metodologias ativas, no campo da formação profissional em saúde, vêm sendo embasadas em duas abordagens freirianas (problematizadoras): Pedagogia da Problematização e Aprendizagem Baseada em Problemas. À primeira, Paulo Freire propõe a construção do conhecimento pelo movimento de agir sobre a realidade; já na segunda, os estudantes reunidos em pequenos grupos são incentivados a utilizar seus conhecimentos prévios na resolução de problemas (MARIN et al. 2010; PARMELEE; MICHAELSEN, 2010; SISK, 2011;
CARCERERI et al., 2014; FREIRE, 2014; SIMON et al. 2014).

O TBL (team-based learning) é uma ferramenta metodológica de ensino inovador que incentiva a aprendizagem ativa dos discentes. Este método integra teoria e prática através de trabalho em equipe, com o objetivo de melhorar a qualidade do ensino, pois tais metodologias levam o aluno a refletir sobre seu processo de ensino, transformando sua realidade, passando pelos diálogos freirianos que possibilitam a participação ativa dos alunos e outras experiências que em muito engrandecem toda a ação ativa (JOHNSON, 2009).

Os benefícios potenciais do TBL incluem maior envolvimento dos alunos, maior qualidade na comunicação e nos processos. A ênfase principal no TBL está na aplicação dos conceitos e processos através do qual os alunos aprendem o conteúdo projetado especificamente para que grupos de estudantes desenvolvam em equipes de aprendizagem autogerida. $\mathrm{O}$ TBL muda o formato de aula que utiliza tradicionalmente o tempo para transmitir conceitos pelo instrutor, para aplicação dos conceitos do curso por pequenas equipes de estudantes não passivos, mas sim participantes ativamente de sua própria aprendizagem (MINAYO, 2001; JOHNSON, 2009).

Diante do exposto faz-se necessário nortear o estudo em TBL como eixo para o desenvolvimento e aplicabilidade em Instituições de Ensino Superior (IES). Contudo, os meios para a sua aplicação carecem de metodologias que visam a "formação humanística, autônoma e formação crítico social". O principal papel da metodologia seria ajudar o aluno na formação de uma cidadania crítica, ativa e altruísta - isso significa que toda teia de relações de ensino constitui o eixo de orientação que trabalha a favor do sujeito crítico social e independente, entendendo as relações que ocorrem consigo e em sua volta, sendo ele objeto ativo do conhecimento humano (THOMPSON et al. 2007; MARIN et al. 2010; PARMELEE; MICHAELSEN, 2010; SISK, 2011).

Nessa lógica este estudo tem como objetivo analisar o uso de metodologia ativa tipo TBL para a prática pedagógica em saúde coletiva no curso de Odontologia.

\section{MATERIAL E MÉTODOS}

Trata-se de uma pesquisa qualitativa sobre o ensino superior em odontologia. Optou-se pelo método, pois, entende-se que responde a questões muito particulares, ou seja, trabalha com o universo de significados, motivos, aspirações, crenças, valores e atitudes, o que corresponde a um espaço mais profundo das relações, dos processos e dos fenômenos que não podem ser reduzidos à operacionalização de variáveis (MINAYO, 2001).

O cenário da pesquisa foi o curso de Odontologia da Universidade Federal do Pará (UFPA), o qual possui carga horária de 4.558 horas segundo a Resolução N ${ }^{\circ} 2$ de 18 de junho de 2007. O universo amostral contou com 447 alunos matriculados em 2014 distribuídos em dez semestres. Sendo que o critério de inclusão para participação eram os alunos matriculados na disciplina de Saúde Coletiva, assim a coleta ocorreu de 2014 a 2016 e 
teve a amostra delineada entre os alunos matriculados somente no 5 semestre, o que totalizou em 150 alunos da Faculdade de Odontologia, sendo 66 alunos em 2014; 58 em 2015 e 26 em 2016. Todos os participantes foram esclarecidos sobre a pesquisa e assinaram termo de consentimento aprovando a participação sendo a pesquisa aprovada no Comitê de Ética em pesquisa do Instituto de Ciências da Saúde da UFPA.

A coleta teve registro em diário de campo e análise de prática didática durante a graduação, com apoio de projeto de monitoria. O TBL foi inserido no ensino da saúde coletiva, a partir de referenciais metodológicos durante disciplina de monitoria na graduação. Para a sua execução houve leitura prévia de artigos e tutoriais indicada aos alunos com posterior aplicação do TBL em sala de aula. Assim, durante todo o semestre, desde o primeiro dia de aula os discentes tiveram acesso a todo o conteúdo a ser trabalhado semanalmente. Em sala de aula, o tempo de duração foi aproximadamente 4 horas, sendo 3 horas para sua execução entre apresentação temática, questões ao grupo e avaliação final. Desse modo, ao final do TBL além da discussão teórica, uma avaliação imediata do conhecimento foi aferida através de gabarito, com preenchimento individual e depois comparada entre os grupos. Os gabaritos foram adaptados e impressos na própria universidade.

A coleta dos dados seguiu em duas etapas: fase1 orientações, princípios e fundamentos do referencial teórico conforme detalhamento do uso do TBL por Sisk (2011); na fase 2 - pesquisa de campo, por meio da observação direta e o diálogo, sendo utilizado roteiro de entrevista estruturado, para posterior análise de diário de campo, baseada em enfoque crítico-dialético. A opção metodológica pela pesquisa qualitativa é pertinente, uma vez que permite considerar todo o contexto da realidade a ser observada, investigando minunciosamente os dados relevantes do universo proposto pelo contato direto do pesquisador com o ambiente e a situação a ser investigada (LUDKE; ANDRÉ, 1986).

$\mathrm{Na}$ primeira fase, os pesquisadores se apropriaram de elocuções científicas, do que se pretendia investigar, ampliando horizonte de percepção, assim como, entendia as possibilidades de pensamentos, de forma que a pesquisa ganhasse subsídios fundamentais para o andamento de todo processo. $\mathrm{O}$ docente e os monitores participaram de curso de metodologias ativas oferecido pela universidade.

$\mathrm{Na}$ segunda fase, seguiu-se em direção à pesquisa de campo, por meio da observação direta e o diálogo, usando um roteiro estruturado, no qual as perguntas centraram-se em como o discente interagiu com a metodologia do TBL, com o professor mediador/facilitador, o monitor e entre os colegas de turma, mostrando suas impressões diante da nova proposta. $\mathrm{O}$ roteiro de entrevista estruturado continha perguntas objetivas com aspectos gerais e específicos para preenchimento de autoresposta. Já para o roteiro de entrevista, considerando que a abordagem qualitativa considera o conteúdo e aprofundamento do significado, foram convidados cinco alunos de cada subturma para garantir representatividade.

O questionário objetivo preocupou-se em conhecer aspectos pessoais (LUDKE; ANDRÉ, 1986). Neste caso, os aspectos dos estudantes, bem como suas vivências, sendo estes constituídos por: sexo, cor, idade, em qual instituição cursou o nível médio e se possuía alguma graduação. Nos aspectos específicos, estes foram constituídos de dez questões. Foram estabelecidos critérios de medidas para avaliação da metodologia, sendo eles: Excelente: muito satisfatório ou perfeito; Bom: satisfatório ou adequado; Regular: bem proporcionado ou executado; Péssimo: mal proporcionado ou executado.

$\mathrm{O}$ roteiro de entrevista, constituiu-se de quatro perguntas, abordando as seguintes elocuções: 1-A partir da experiência vivenciada por você, como avalia a metodologia empregada em sua turma, foi satisfatória? Sobre que aspecto? 2-Na aprendizagem adquirida durante o semestre você se considerou parte ativa desse processo? Por quê?3-A respeito do conteúdo que foi ministrado, recorde um dos assuntos exposto nas aulas? 4-Você recomendaria o TBL em outras disciplinas? Justifique?

Os presentes roteiros estruturados foram aplicados ao término de cada semestre, para toda a turma, de acordo com o turno, matutino e vespertino. As entrevistas foram individuais, gravadas e posteriormente transcritas pelos monitores da disciplina. Em seguida analisados pelo docente e monitores.

Todas as etapas da pesquisa seguiram a ética em pesquisa para seres humanos tendo aprovação, sob a égide da Resolução 466/12_nº 1.349.225.

\section{RESULTADOS E DISCUSSÃO}

Os resultados de todas as etapas sobre a visão da universidade em análise crítico-dialética, remeteu-se a uma reflexão sobre a educação superior realizada por meio do ensino, da pesquisa e da extensão, de forma indissociável, visando o aperfeiçoamento cultural do ser humano. Assumindo assim, a proposta de capacitá-lo para o exercício da profissão, de modo a prepará-lo para a reflexão crítica e a participação na produção, sistematização e superação do saber. A busca por subsídios, para assegurar as propostas da política universitária, tem sido constante, principalmente na área da saúde, no que tange o ensino de saúde coletiva. Esse processo define ações a serem desenvolvidas, as quais incorporem e comprometam-se com as transformações e as exigências do ensino (FREIRE, 2014).

Notou-se que a inserção da metodologia ativa (TBL), mostra a inovação dentro do cotidiano da aprendizagem. Observa-se suas amplitudes positivas e bem aceitas, frente aos conteúdos administrados na rotina dos alunos.

O uso da metodologia ativa para a prática pedagógica em saúde coletiva em curso de Odontologia obteve excelentes resultados, com $80 \%$ de aceitabilidade. Este percentual foi observado nas respostas do roteiro objetivo, com resultado bom e excelente; assim como no roteiro subjetivo. Ressalta-se que as respostas deste elucidaram que eles estavam à vontade para discutir, ouvir e aprender, com a metodologia, enfatizando que esta oportunizava cada um ser autor da própria aprendizagem (Quadro1). 
Quadro 1. Falas extraídas da análise de conteúdo das entrevistas com os participantes no período de 2014 a 2016 em Belém, Pará

"[...] em disciplinas com um grau de leitura acentuado, com conteúdos voltados para as áreas de pesquisas, é interessante o uso do TBL, pois as discussões e debates gerados pelo TBL geram respostas convincentes e tiram dúvidas [...]" (ALUNO 1).

“... gostei muito do processo, por que me senti uma parte muito essencial dele, eu construí meus conceitos a partir do que foi estudado em casa e consolidei em aula." (ALUNO 2)

“[...] pude expor minhas dúvidas e argumentos durante os tbls, por isso me considero parte ativa durante as discussões em sala [...]”" (ALUNO 3)

“O sistema de avaliação do TBL é muito bom, pois integra todos os assuntos elaborados em uma aula tanto individualmente como coletivamente[...]” (ALUNO 4)

“A experiência foi satisfatória, onde debates em grupo estimularam a aprendizagem, dividindo e multiplicando conhecimentos." (ALUNO 5)

“O TBL é uma estratégia válida para melhor fixação do conhecimento abordado em sala de aula, pois exige um estudo prévio, é bem dinâmico." (ALUNO 6)

Notou-se que os discentes aprovaram a metodologia, sentindo-se motivados pela forma de condução e pela apropriação do conhecimento, o que permite dizer, que o método é seguro e eficiente, e, sobretudo, aceito por aqueles que foram oportunizados de ter protagonizado. Vivenciar as práticas educativas como esta, contribui em muito para o desenvolvimento da educação.

Com o diário de campo em associação com o roteiro estruturado, evidenciaram-se, carências e motivações, produzidas pelo TBL. À medida que compreendidas, as limitações foram sanadas, revisadas e corrigidas, nos aspectos positivos, isto é, aperfeiçoadas para serem reinseridas no semestre seguinte. Considerou-se essencial às etapas vivenciadas em todo o decurso desse processo, otimizando assim, o tempo dos atores envolvidos. Por ter sido o TBL aplicado unicamente na saúde coletiva, o quadro docente da instituição desconhece o processo, portanto, este ainda não foi consultado a respeito de sua execução.

Considerando que o ensino universitário público é uma instituição democrática, e deve garantir a todos o direito formativo social, sendo esta à meta essencial da educação, faz-se necessário encontrar meios que venham ajudar os alunos a enfrentar tarefas e desafios que os aguardam na sociedade, superando a conservadora aquisição de conhecimentos pontuais e concretos. É possível acrescentar muitas outras competências interpessoais, afetivas e sociais, que a universidade fomentará em seus discentes, a partir de uma metodologia pautada em propostas como essa, que tem seu cerne na participação de todos os envolvidos no processo de ensino-aprendizagem com metodologias ativas (MICHAELSEN, 2002; SISK, 2011).

Sabe-se, contudo, que o ensino na área de saúde, como a Odontologia no Brasil, baseou-se na prática norteamericana - a primeira escola foi em Baltimore, Estados Unidos, em 1841. O modelo profissional difundido era do "profissional liberal", seguindo o modelo das práticas individualizadas, de um determinado grupo ou de cunho individual (VALENÇA, 1998).
Assim, a proposta de trabalho nessas linhas, oportuniza a discussão as características singulares de cada contexto educativo, uma vez que, diferentes sujeitos formam o centro universitário como um todo. Neste propósito, vislumbra-se uma educação universitária, que não apenas possibilite o acesso às informações, mas que também ofereça aos discentes, oportunidade de discutir, participar verdadeiramente do processo de aprendizagem, sem substituir ou omitir o docente de sua função. É preciso não confundir democracia com ingenuidade. A ação sobre todos os indivíduos envolvidos nesse processo deverá preservar o bem comum, sendo este o objetivo essencial do Estado democrático, no qual os deveres e direitos devem ser igualmente distribuídos (OLIVEIRA, 1997; VALENÇA, 1998, FREIRE, 2014).

Nesse particular, busca-se que a sociedade acadêmica vivencie a informação e a participação, pois são pontos que solidificam a democracia. Democratizar o processo de aquisição do conhecimento requer, fundamentalmente, que a sociedade possa participar do processo de formulação e avaliação de sua aprendizagem, assim como na fiscalização de sua execução, por meio de mecanismos ativos, como TBL. A presença de tal método materializa-se por meio da incorporação de todos os envolvidos direta ou indiretamente no processo de aprendizagem, que, normalmente estão excluídos das decisões (discentes), ou seja, significa ampliar as possibilidades de ensino, fazendo dos discentes, "coautores" de sua aprendizagem, e redirecionando o docente no monopólio de determinar os rumos do ensino. $\mathrm{O}$ estudante (aprendiz) não recebe o conhecimento ou habilidade numa via unidirecional, mas participa juntamente com o mestre na produção deste (SIMON et al., 2014).

O ensino universitário que se busca, requer uma mudança urgente, porém serena (pacífica) da cultura metodológica atual, e toda essa discussão inicia dentro da sala de aula, com métodos adotados pelos docentes, e que sejam considerados democráticos, entendidos como mais participativos, que contemplam a não concentração de 
certas decisões e a descentralização dos serviços (OLIVEIRA, 1997).

Essa mudança na prática educativa instiga os sujeitos envolvidos a repensar a organização e vivência social nas universidades como um elemento favorecedor, embora não determinante de outras práticas ativas. Nessa abordagem, a aprendizagem passa a ser entendida como elo entre docente e discente. Isso traz um conjunto de tarefas especificamente organizadas, o que rentabiliza todo o processo, já que a aprendizagem aqui entendida é produto de longa evolução histórica e traz a marca das contradições sociais e dos interesses políticos em jogo na sociedade (PARO, 2002).

Assim, a formação odontológica tenta fugir daquele profissional liberal que vende seus serviços em troca de quem pode pagar, "marginalizando" a população que busca e necessita de tais serviços. De tal modo, sua ênfase é no modelo curativo, em função do alto custo o que desvincula das reais urgências e carências da saúde oral do país (VALENÇA, 1998).

Diante dessa concepção simplista, a formação proposta não privilegia a prevenção da saúde bucal, nem tampouco, a formação "por inteiro" do aluno de odontologia - a teia de relações constitui um eixo de orientação que não trabalha em conformidade, mas em favor da cidadania, autonomia e prevenção. Não cria um serviço de orientação para atender aos excluídos, (seja de comportamento, de procedimentos, de conhecimento), de modo, que para atendê-los através das relações que ocorrem (poder/saber, fazer/saber), é necessário um ensino para além da técnica e método, para a autonomia e para o coletivo, em favor de todos e de cada um (VALENÇA, 1998).

Para tanto, implementar um "bom" currículo universitário, não supre às profundas contradições e distorções referentes ao assunto em discussão Para realizar tais tarefas, entende-se que permanecem ainda atuais, os desafios de democratização e autonomia de estrutura universitária, a fim de garantir o desempenho da universidade enquanto instituição estratégica do social (VALENÇA, 1998; FREIRE, 2014).

Nesse sentido, as mudanças nas práticas educativas têm sido pautadas em metodologias ativas, como TeamBased Laerning (TBL), com interações saudáveis e responsáveis dentro do grupo, segundo Sisk (2011), Michaelsen et al.(2002) que desenvolveram um interessante método de aprendizagem ativa, chamado Aprendizagem Baseada em Equipes (TBL), o qual vem sendo utilizado em diversas áreas, e mostrando a aceitação, assim como, o efeito positivo do método na prática educativa dos discentes.

Todavia, o método ativo, TBL, é pouco difundido no Brasil, nos estudos realizados, sem considerações expressivas para serem mencionadas. Acredita-se, que tal metodologia é uma inovação diversificada e flexível, de tempo e aprendizagem do discente, harmonizando conteúdo e estrutura, desenvolvendo interações grupais e sociais de relações, de intercâmbio e convivência coletiva. Isso supõe construir juntos o conhecimento. Nessa via acredita ser de vital importância mensurar e avaliar a satisfação dos alunos de maneira confiável e válida, após a aplicação do TBL, uma vez que são ações e discursos democráticos que encontram utilidade e significado na difícil relação da aprendizagem (SISK, 2011).

A presente metodologia não encerra ou limita as discussões sobre métodos ativos, como o TBL, mas abre caminhos para novas elaborações e mudanças nos paradigmas vigentes no ensino, entendendo que somente uma orientação contextualizada poderá mostrar a efetividade do método aplicado no ensino, dispondo de um papel aliado ao ensino e à participação.

Freire (2014) vislumbrava para uma prática aberta e ativa, sendo que a prática educativa é tudo isso: afetividade, alegria, capacidade científica, domínio técnico à serviço da mudança. Ressignificar o ensino e a aprendizagem envolve diretamente repensar a prática e seu conteúdo. Assim, o ato de ensinar inclui a concepção de métodos que testem e aperfeiçoem o ensino, desta forma, investigações científicas relacionadas à TBL oferecem recursos e oportunidades para que professores trabalhem juntos e demonstrem a efetividade desse método (SISK, 2011).

\section{CONCLUSÃO}

Há um impacto positivo no uso do TBL para a prática pedagógica em saúde coletiva no curso de Odontologia, permitindo recomendar o uso da metodologia ativa para outras disciplinas do currículo, sendo um método inovador, competente e satisfatório no ensino, com plena aceitabilidade dos discentes.

\section{REFERÊNCIAS}

BRASIL. Ministério da Educação. Conselho Nacional de Educação. Câmara de Educação Superior. Parecer $n^{\circ}$. 1.300. Diretrizes Curriculares Nacionais dos Cursos de Graduação em Farmácia e Odontologia. Brasília, DF, 06 nov. 2001. Seção 1, p. 25. Disponível em: <http://portal.mec.gov.br/cne/arquivos/pdf/CES1300.pdf> . Acesso em: 08 abr. 2016.

CARCERERI, D. L.; PADILHA, A. C. L.; BASTOS, R. C. Fatores relevantes para a mudança na formação em Odontologia motivados pelo Programa Nacional de Reorientação da Formação Profissional em Saúde (PróSaúde). Revista da ABENO, v. 14, p. 1, p. 94-106, 2014.

FREIRE, P. Pedagogia da autonomia: saberes necessários à prática da educativa. 49. ed. Rio de Janeiro: Paz e Terra, 2014.

JOHNSON, C. Review of book Team-Based Learning for Health Professions Education: A Guide to Using Small Groups for Improving Learning by Michaelsen, L. K.; Parmelee, D.X.; McMahon, K. K.; Ruth E. Levine, R. E. editors Foreword by Diane M. Billings. Sterling [VA]: Stylus Publishing, LLC; 2007. The Journal of Chiropractic Education. v. 23, n. 1, p. 47-48, Spring, 2009. PMCID: PMC2670235.

LUDKE, M.; ANDRÉ, M. E. D. A. Pesquisa em educação: abordagens qualitativas (Temas básicos de educação e ensino). São Paulo: EPU, 1986. 
MARIN, M. J. S.; GOMES, G.; MARVULO, M. M. L.; PRIMO, E. M.; BARBOSA, P. M. K.; DRUZIAN, S. Pósgraduação multiprofissional em saúde: resultados de experiências utilizando metodologias ativas. Interface Comunicação, Saúde, Educação, v.14, n.33, p.331-44, abr./jun. 2010. http://dx.doi.org/10.1590/S141432832010000200008 .

MICHAELSEN, L. K.; KNIGHT, A. B.; FINK, L. D. Team-Based Learning: A Transformative Use of Small Groups. 1. ed. Greenwood Publishing Group, 2002.

MINAYO, M. C. S. Pesquisa Social. Teoria, método e criatividade. 18. ed. Petrópolis: Vozes, 2001.

OLIVEIRA, D. A. (org.). Gestão democrática da educação. 8. ed. Petrópolis (RJ): Vozes, 1997.

PARMELEE, D. X.; LARRY, K..; MICHAELSEN, L. K.. Twelve tips for doing effective Team-Based Learning (TBL).Medical Teacher. v. 32, p. 118-122, 2010. Disponível em: <http://site.ufvjm.edu.br/fammuc/files/2016/05/TBL3.pdf $>$.
PARO, V. H. Administração Escolar: introdução crítica. 11. ed. São Paulo: Cortez; 2002.

SIMON, E.; JEZINE, E.; VASCONCELOS, E. M.; RIBEIRO, K. S. Q. S. Metodologias ativas de ensinoaprendizagem e educação popular: encontros e desencontros no contexto da formação dos profissionais de saúde.Interface (Botucatu), v. 18, n. 2, p. 1355-1364, 2014.

SISK, R. J. Team-Basead Learning: Systematic Research Review. Journal of Nursing Education, v. 50, n. 12, p. 665-9, 2011.

THOMPSON, B. M.; SCHNEIDER, V. F.; HAIDET, P.; LEVINE, R. E.; MCMAHON, K. K.; PERKOWSKI, L. C.; RICHARDS, B. F. Team-based learning at ten medical schools: two years later. Medical Education, v. 41, p. 250257, 2007. http://dx.doi.org/10.1111/j.13652929.2006.02684.x.

VALENÇA, A. M. G. A educação em saúde na formação do cirurgião - dentista: da necessidade à prática participativa. 1. ed. Niterói: EdUFF. 1998. 